\title{
Variety in fruit and vegetable consumption and 10-year incidence of $\mathrm{CHD}$ and stroke
}

\author{
Linda M Oude Griep ${ }^{1}$, WM Monique Verschuren ${ }^{2}$, Daan Kromhout ${ }^{1}$, Marga C Ocké ${ }^{3}$ \\ and Johanna M Geleijnse ${ }^{1, *}$ \\ 'Division of Human Nutrition, Wageningen University, PO Box 8129, 6700 EV Wageningen, the Netherlands: \\ ${ }^{2}$ Center for Prevention and Health Services Research, National Institute for Public Health and the Environment, \\ Bilthoven, the Netherlands: ${ }^{3}$ Center for Nutrition and Health, National Institute for Public Health and the \\ Environment, Bilthoven, the Netherlands
}

Submitted 20 May 2011: Final revision received 12 0ctober 2011: Accepted 17 February 2012: First published online 23 March 2012

\begin{abstract}
Objective: Consuming a variety of fruit and vegetables provides many different micronutrients and bioactive compounds. Whether this contributes to the beneficial association between fruit and vegetables and incident CHD and stroke is unknown. Design: Prospective population-based cohort study.

Setting: The Netherlands.

Subjects: Men and women ( $n$ 20 069) aged 20-65 years. Participants completed a validated 178 -item FFQ, including nine fruit and thirteen vegetable items. Variety in fruit and vegetables was defined as the sum of different items consumed at least once per 2 weeks over the previous year. Hazard ratios (HR) for variety in relation to incident CHD and stroke were calculated using multivariable Cox proportional hazards models additionally adjusted for quantity of fruit and vegetables.

Results: Variety and quantity in fruit and vegetables were highly correlated $(r=0 \cdot 81)$. Variety was not associated with total energy intake $(r=-0 \cdot 01)$ and positively associated with nutrient intakes, particularly vitamin C $(r=0 \cdot 70)$. During 10 years of follow-up, 245 cases of CHD and 233 cases of stroke occurred. Variety in vegetables (HR per 2 items $=1 \cdot 05$; 95\% CI 0.94, 1.17) and in fruit (HR per 2 items $=1 \cdot 00 ; 95 \%$ CI $0 \cdot 87,1 \cdot 15)$ were not related to incident CHD. Variety in vegetables (HR per 2 items $=0.93 ; 95 \%$ CI $0.83,1.04$ ) and in fruit (HR per 2 items $=1 \cdot 03 ; 95 \%$ CI $0 \cdot 89,1 \cdot 18)$ were also not related to incident stroke.

Conclusions: More variety in fruit and vegetable consumption was associated with higher intakes of fruit and vegetables and micronutrients. Independently of quantity, variety in fruit and vegetables was related neither to incident CHD nor to incident stroke.
\end{abstract}

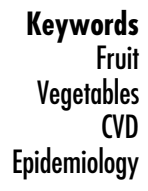

Not only total fruit and vegetable consumption, but also variety of fruit and vegetables could be important for cardiovascular prevention. Consuming a variety of fruit and vegetables provides many different micronutrients and bioactive compounds that may underlie the observed inverse associations with $\mathrm{CVD}^{(1-4)}$. Findings of randomized controlled trials showed that increasing fruit and vegetable intakes effectively increased plasma levels of carotenoids and vitamin $\mathrm{C}^{(5-7)}$. However, intervention studies focusing on single nutrients abundant in fruit and vegetables failed to demonstrate beneficial effects on $\mathrm{CVD}^{(8,9)}$. Eating more fruit and vegetables may therefore be cardioprotective through various mechanisms. There is evidence from intervention studies that a diet rich in fruit and vegetables may favourably affect blood pressure levels ${ }^{(7,10)}$. Possibly, the combined or even synergistic effects of different bioactive components in their natural food matrix may be important in the prevention of $\mathrm{CVD}^{(11)}$. In this context, the 2010 Dietary Guidelines for Americans recommends besides a diet rich of fruit and vegetables, also to choose a variety daily $^{(12)}$.

Different aspects of fruit and vegetable consumption, e.g. amount, processing, colour and variety, may contribute to the inverse association between fruit and vegetables and incident CHD and stroke. Previously, we found that both raw and processed fruit and vegetables and deep orange fruit and vegetables may protect against $\mathrm{CHD}^{(13,14)}$. With regard to stroke, inverse associations were observed for intake of raw and white fruit and vegetables $^{(15,16)}$. To the best of our knowledge, there are no previous prospective cohort studies that have yet evaluated associations between fruit and vegetable variety 
and the risk of incident CHD and stroke. Results from a cross-sectional study showed that fruit and vegetable variety but not quantity was associated with less inflammation and with a lower risk of CHD using the Framingham Risk Score ${ }^{(17)}$. In cancer research, several prospective cohort studies have investigated the importance of variety in fruit and vegetables, but no associations were observed between variety in fruit and vegetables and incidence of total cancer or subtypes ${ }^{(18-21)}$. Inverse associations were found only between vegetable variety and total cancer and non-lung epithelial cancer ${ }^{(19)}$. In the present study, we examined the associations between variety in fruit and vegetable consumption with 10-year incident CHD and stroke in a population-based cohort study in the Netherlands.

\section{Materials and methods}

\section{Study population}

The present study was conducted in a Dutch populationbased cohort of men and women aged 20 to 65 years: the Monitoring Project on Risk Factors and Chronic Diseases in the Netherlands (MORGEN) Study. The baseline measurements including dietary assessment were carried out between 1993 and $1997^{(22)}$. The Medical Ethics Committee of the Netherlands Organization for Applied Scientific Research (TNO) approved the study protocol and all participants signed informed consent. Of 22654 participants, we excluded respondents without informed consent for vital status follow-up ( $n$ 701), who did not fill out an FFQ ( $n 72)$, with reported total energy intake $<2094$ or $>18844 \mathrm{~kJ} / \mathrm{d}$ for women or $<3350$ or $>20938 \mathrm{~kJ} / \mathrm{d}$ for men ( $n 97)$, with prevalent myocardial infarction or stroke ( $n$ 442) and those with self-reported diabetes or using lipid-lowering or antihypertensive drugs ( $n$ 1273). This resulted in a study population of 20069 participants, including 8988 men and 11081 women.

\section{Dietary assessment}

Information on habitual consumption of 178 food items, covering the previous year, was collected at baseline using a validated, self-administered and semi-quantitative FFQ developed for the Dutch cohorts of the European Prospective Investigation into Cancer and Nutrition (EPIC) ${ }^{(23)}$. Participants indicated their consumption as absolute frequencies in times per day, per week, per month, per year or as never. For several food items, additional questions were included about consumption frequency of different sub-items or preparation method using the following categories: always/mostly, often, sometimes and seldom/ never. Consumed amounts were calculated using standard household measures, natural units or portion sizes indicated by colour photographs. The photographs showed different portion sizes to assess consumed quantities of twenty-one food items, mainly vegetables. Frequencies per day and portion sizes were multiplied to obtain grams per day for each food item. The Dutch food composition database of 1996 was used to calculate values for energy and nutrient intakes ${ }^{(24)}$.

The fruit and vegetables assessed were those commonly consumed in the Netherlands. Fruit and vegetable consumption during winter and summer were assessed separately to take seasonal variation into account. Fruit and vegetable juices and sauces were excluded and we did not consider potatoes and legumes as vegetables, because their nutritional value differs significantly from that of vegetables ${ }^{(24)}$.

The reproducibility of the FFQ after 12 months was expressed as Spearman's correlation coefficients and were 0.76 in men and 0.65 in women for vegetable intake and 0.61 in men and 0.77 in women for fruit ${ }^{(23)}$. The validity against twelve repeated $24 \mathrm{~h}$ recalls varied between 0.31 and 0.38 for vegetables and between 0.56 and 0.68 for fruit.

\section{Variety}

The FFQ comprised nine fruit items, seven raw vegetables and thirteen cooked vegetables. Each different fruit or vegetable that was consumed at least once per 2 weeks over the previous year contributed 1 point to the variety score. Several vegetable items that were essentially the same food but appeared in different forms, e.g. raw and cooked carrots, contributed only 1 point if their combined intake was at least once per 2 weeks. Several items were combined in single questions and could therefore not be distinguished from one another, i.e. apples and pears, cabbages, and leeks and onions. Variety scores ranged from 0 to 22 for fruit and vegetables together, from 0 to 9 for fruit, and from 0 to 13 for vegetables.

\section{Risk factors}

Body weight, height and blood pressure of the participants were measured by trained research assistants during a physical examination at a municipal health service site. Non-fasting venous blood samples were collected, and serum total and HDL cholesterol concentrations were determined using an enzymatic method. Information on cigarette smoking, educational level, physical activity, use of antihypertensive and lipid-modifying drugs, ever use of hormone replacement therapy and both the participants' and their parents' history of acute myocardial infarction (AMI) were obtained by a self-administered questionnaire. Dietary supplement use (yes/no) and alcohol intake were obtained from the FFQ. Alcohol intake was expressed as the number of glasses of beer, wine, port wine and strong liquor consumed per week. From 1994 onwards, physical activity was assessed using a validated questionnaire that was developed for the EPIC study ${ }^{(25)}$. Physical activity was defined as engaging in activities with an intensity of $\geq 4$ metabolic equivalents on at least $5 \mathrm{~d} /$ week for at least $30 \mathrm{~min}$. 


\section{Ascertainment of fatal and non-fatal events}

Information on the participants' vital status up to 1 January 2006 was monitored using the municipal population register. Information on the primary cause of death was obtained from Statistics Netherlands. The hospital discharge register provided clinically diagnosed AMI and stroke admissions. In a validation study, 84\% of the AMI cases in the cardiology information system of the University Hospital Maastricht corresponded with AMI cases identified in the hospital discharge register ${ }^{(26)}$. CHD incidence was defined as non-fatal AMI event or fatal CHD event. Similarly, incident stroke was defined as non-fatal or fatal stroke event. Fatal CHD as the primary cause of death included codes I20-I25 of the tenth revision of the International Classification of Diseases (ICD-10) and non-fatal AMI comprised code 410 of the ninth revision of the International Classification of Diseases (ICD-9). Fatal stroke comprised ICD-10 codes I60-I67 and 169 and non-fatal stroke including transient ischaemic attack comprised ICD-9 codes 430-438. If the dates of hospital admission and death coincided the event was considered fatal.

\section{Statistical analyses}

For each participant we calculated person-time from date of enrolment until the first event (incident CHD or stroke), date of emigration ( $n$ 693), date of death or censoring date (1 January 2006), whichever occurred first. Correlations between variety score in fruit and vegetable items and intake of selected foods and nutrients were calculated using the Spearman rank correlation test.

Participants were divided into tertiles of variety scores. We used multivariable Cox proportional hazards models to estimate hazard ratios (HR) for the incidence of CHD and stroke for each tertile of variety compared with the lowest and continuously per increase of 2 or 4 items. The Cox proportional hazards assumption was fulfilled in all models according to the graphical approach and Schoenfeld residuals.

Besides an age- (continuous) and gender-adjusted model, we used a multivariable model that included total energy intake $(\mathrm{kJ})$, smoking status (never, former, current smoker of $<10,10-19$, $\geq 20$ cigarettes/d), alcohol intake (never, moderate or high consumption, i.e. $>1$ glass $/ \mathrm{d}$ in women and $>2$ glasses/d in men), educational level (four categories), dietary supplement use (yes/no), past or present use of hormone replacement therapy (yes/no), family history of premature AMI (before 55 years of the father or before 65 years of the mother, yes/no) and BMI $\left(\mathrm{kg} / \mathrm{m}^{2}\right)$. Additionally, we extended the model with dietary covariates including intakes of wholegrain foods $(\mathrm{g} / \mathrm{d})$, processed meat $(\mathrm{g} / \mathrm{d})$ and fish (quartiles) and quantity of fruit and vegetable consumption $(\mathrm{g} / \mathrm{d})$. For participants enrolled from 1994 onwards, we evaluated whether physical activity was a potential confounder ('active' being defined as engagement in cycling or sports of $\geq 4$ metabolic equivalents) by comparing HR with and without adding physical activity to the multivariable model.

Stratified analyses and the log-likelihood test using cross-product terms in the multivariable models showed no evidence for potential effect modification by age ( $<50$ years $v$. $\geq 50$ years), gender or smoking status (never including former $v$. current). Two-tailed $P$ values $<0.05$ were considered statistically significant. Analyses were performed using the SAS statistical software package version 9.2 (SAS Institute, Inc., Cary, NC, USA).

\section{Results}

Participants with a greater variety in fruit and vegetable consumption were more often women, had a higher educational level, were less likely to smoke, more likely to be physically active and used dietary supplements more often (Table 1). The mean scores for each tertile of variety in fruit and vegetables were 5.7, 10.5 and $15 \cdot 3$, respectively. Fruit and vegetable intake was $2 \cdot 5$-fold higher among participants in the highest compared with the lowest tertile of variety. Variety was strongly correlated with total fruit and vegetable intake (Spearman's $r=0 \cdot 81, P<0 \cdot 0001$ ) and with fruit intake (Spearman's $r=0 \cdot 72, P<0 \cdot 0001)$, and less strongly with vegetable intake (Spearman's $r=0.53, P<0.0001$ ). Greater variety in fruit and vegetable consumption was not associated with total energy intake and positively associated with intakes of vitamin $\mathrm{C}$, carotenoids, flavonoids and dietary fibre (Table 2). Eighty per cent of the population consumed apples and pears, citrus fruit, cabbages and allium vegetables at least once per 2 weeks over the previous year.

During 10 years of follow-up, we documented 245 first cases of CHD of which thirty-four were fatal. Furthermore, 233 first cases of stroke occurred (seven fatal cases) of which 139 were ischaemic, forty-five haemorrhagic and forty-nine other or unspecified strokes. After adjustment for age and gender, variety in fruit (Table 3; HR per 2 items $=0 \cdot 87 ; 95 \% \mathrm{CI} 0 \cdot 80,0 \cdot 95)$ and variety in fruit and vegetables (HR per 4 items $=0 \cdot 86 ; 95 \%$ CI $0 \cdot 77,0 \cdot 98$ ) were inversely associated with incident CHD. However, after adjustment for lifestyle and dietary factors including quantity of fruit and vegetables, fruit variety (HR per 2 items $=1 \cdot 00 ; 95 \%$ CI $0 \cdot 87,1 \cdot 15)$, vegetable variety (HR per 2 items $=1.05 ; 95 \%$ CI $0.94,1 \cdot 17$ ) and their combination (HR per 4 items $=1 \cdot 07$; $95 \%$ CI 0.89, 1.29) were not significantly associated with incident CHD.

After adjustment for age and gender, fruit variety (Table 4; HR per 2 items $=0.92 ; 95 \%$ CI $0 \cdot 84,1 \cdot 00)$, vegetable variety (HR per 2 items $=0.89 ; 95 \%$ CI $0.80,0.99$ ) and their combination (HR per 4 items $=0 \cdot 85 ; 95 \%$ CI $0.75,0.96)$ were inversely associated with incident stroke. After adjustment for lifestyle and dietary factors, 
Table 1 Demographic and lifestyle characteristics ${ }^{*}$ by tertile of variety in fruit and vegetable consumption among 20069 Dutch men and women aged $20-65$ years

\begin{tabular}{|c|c|c|c|c|c|c|}
\hline & \multicolumn{2}{|c|}{$\begin{array}{c}\mathrm{T} 1 \\
(n 6768)\end{array}$} & \multicolumn{2}{|c|}{$\begin{array}{c}\text { T2 } \\
(n \text { 6571) }\end{array}$} & \multicolumn{2}{|c|}{$\begin{array}{c}\text { T3 } \\
(n 6730)\end{array}$} \\
\hline & Mean or \% & SD & Mean or \% & SD & Mean or \% & SD \\
\hline Variety score, mean & $5 \cdot 7$ & $2 \cdot 0$ & $10 \cdot 5$ & $1 \cdot 1$ & $15 \cdot 3$ & 1.9 \\
\hline Age (years) & $41 \cdot 0$ & $11 \cdot 2$ & $41 \cdot 5$ & $11 \cdot 2$ & $42 \cdot 0$ & $10 \cdot 8$ \\
\hline Men (\%) & $56 \cdot 7$ & - & $45 \cdot 1$ & - & $32 \cdot 5$ & - \\
\hline Low educational levelt (\%) & $55 \cdot 0$ & - & $46 \cdot 9$ & - & $38 \cdot 8$ & - \\
\hline Current smokers (\%) & $43 \cdot 3$ & - & $35 \cdot 4$ & - & $31 \cdot 0$ & - \\
\hline Moderate alcohol consumersł (\%) & $53 \cdot 7$ & - & $58 \cdot 1$ & - & $58 \cdot 7$ & - \\
\hline High alcohol consumers§ (\%) & $31 \cdot 6$ & - & $30 \cdot 0$ & - & $31 \cdot 1$ & - \\
\hline Dietary supplement use (\%) & $25 \cdot 5$ & _- & $30 \cdot 8$ & _ & $36 \cdot 3$ & _ \\
\hline Physically active\| (\%) & $26 \cdot 5$ & _- & $31 \cdot 8$ & - & $37 \cdot 4$ & \\
\hline $\mathrm{BMl}\left(\mathrm{kg} / \mathrm{m}^{2}\right)$ & $25 \cdot 1$ & $4 \cdot 0$ & $24 \cdot 8$ & $3 \cdot 8$ & $24 \cdot 7$ & $3 \cdot 7$ \\
\hline Serum total cholesterol $(\mathrm{mmol} / \mathrm{l})$ & $5 \cdot 3$ & $1 \cdot 1$ & $5 \cdot 2$ & $1 \cdot 1$ & $5 \cdot 2$ & $1 \cdot 1$ \\
\hline Serum HDL cholesterol (mmol/li) & $1 \cdot 3$ & 0.4 & $1 \cdot 4$ & 0.4 & $1 \cdot 4$ & 0.4 \\
\hline Systolic blood pressure $(\mathrm{mmHg})$ & 121 & 16 & 120 & 15 & 119 & 15 \\
\hline Family history of AMI (\%) & $9 \cdot 2$ & - & $9 \cdot 0$ & - & $9 \cdot 0$ & - \\
\hline Ever use of hormone replacement therapy in women (\%) & $3 \cdot 4$ & - & $4 \cdot 6$ & - & $6 \cdot 7$ & - \\
\hline
\end{tabular}

AMI, acute myocardial infarction.

*Data are presented as mean and standard deviation or percentage.

tDefined as primary school and lower, intermediate general education.

‡Defined as $0<$ glass $/ \mathrm{d} \leq 1$ in women and as $0<$ glass $/ \mathrm{d} \leq 2$ in men.

§Defined as $>1$ glass/d in women and $>2$ glasses/d in men.

\|Defined as engagement in cycling or sports of $\geq 4$ metabolic equivalents, in a subsample of participants enrolled from 1994 onwards ( $n$ 15 433 ).

-Defined as occurrence of AMI before 55 years of the father or before 65 years of the mother.

Table 2 Daily intakes (mean and standard deviation) of selected foods and nutrients by tertile of variety in fruit and vegetable consumption among 20069 Dutch men and women aged 20-65 years

\begin{tabular}{|c|c|c|c|c|c|c|c|}
\hline & \multicolumn{2}{|c|}{$\begin{array}{c}\text { T1 } \\
(n \text { 6768) }\end{array}$} & \multicolumn{2}{|c|}{$\begin{array}{c}\text { T2 } \\
\text { (n 6571) }\end{array}$} & \multicolumn{2}{|c|}{$\begin{array}{c}\text { T3 } \\
\text { (n 6730) }\end{array}$} & \multirow[b]{2}{*}{$r^{*}$} \\
\hline & Mean & SD & Mean & SD & Mean & SD & \\
\hline Variety score (mean) & $5 \cdot 7$ & & $10 \cdot 5$ & & $15 \cdot 3$ & & \\
\hline Fruit and vegetables $(\mathrm{g} / \mathrm{d})$ & 155 & 69 & 259 & 98 & 393 & 141 & 0.81 \\
\hline Fruit $(g / d)$ & 67 & 60 & 144 & 101 & 248 & 131 & 0.72 \\
\hline Vegetables $(\mathrm{g} / \mathrm{d})$ & 88 & 38 & 115 & 43 & 145 & 52 & 0.53 \\
\hline Wholegrain foods (g/d) & 51 & 71 & 64 & 73 & 73 & 70 & $0 \cdot 18$ \\
\hline Processed meat $(\mathrm{g} / \mathrm{d})$ & 48 & 36 & 44 & 33 & 39 & 31 & $-0 \cdot 14$ \\
\hline Fish $(g / d)$ & 8 & 9 & 10 & 10 & 12 & 12 & $0 \cdot 18$ \\
\hline Energy $(\mathrm{kJ} / \mathrm{d})$ & 9470 & 2793 & 9612 & 2833 & 9452 & 2755 & -0.01 \\
\hline Protein (\% of energy) & 15 & 2 & 15 & 2 & 15 & 2 & $0 \cdot 10$ \\
\hline Fat (\% of energy) & 36 & 5 & 36 & 5 & 35 & 5 & $-0 \cdot 15$ \\
\hline SFA ( $\%$ of energy) & 15 & 3 & 15 & 2 & 14 & 2 & $-0 \cdot 16$ \\
\hline PUFA (\% of energy) & 7 & 2 & 7 & 2 & 7 & 2 & 0.04 \\
\hline Carbohydrates (\% of energy) & 45 & 6 & 45 & 6 & 46 & 6 & $0 \cdot 13$ \\
\hline Dietary fibre $(\mathrm{g} / \mathrm{d})$ & 22 & 7 & 25 & 7 & 27 & 7 & 0.31 \\
\hline Vitamin $C(\mathrm{mg} / \mathrm{d})$ & 75 & 27 & 104 & 34 & 141 & 45 & 0.70 \\
\hline$K(g / d)$ & 3.6 & $1 \cdot 0$ & 3.9 & $1 \cdot 0$ & $4 \cdot 1$ & $1 \cdot 0$ & 0.21 \\
\hline Carotenoids (mg/d) & $7 \cdot 9$ & $3 \cdot 3$ & $9 \cdot 4$ & $3 \cdot 6$ & $11 \cdot 1$ & $4 \cdot 3$ & 0.39 \\
\hline Flavonoids (mg/d) & $43 \cdot 1$ & $39 \cdot 3$ & $54 \cdot 3$ & $41 \cdot 9$ & $66 \cdot 7$ & $44 \cdot 8$ & 0.32 \\
\hline
\end{tabular}

*Spearman's correlation coefficients were calculated between variety score in fruit and vegetable consumption and intake of selected foods and nutrients. Corresponding $P$ values for correlation coefficients were statistically significant $(P<0.0001)$ except for energy intake $(P=0 \cdot 20)$. Adjustment for total energy intake showed similar Spearman's correlation coefficients except for dietary fibre $(r=0 \cdot 42)$ and $\mathrm{K}(r=0 \cdot 35)$.

these associations became not statistically significant. We observed that fruit variety (HR per 2 items $=1 \cdot 03 ; 95 \%$ CI: $0 \cdot 89,1 \cdot 18)$ and the combination of fruit and vegetable variety (HR per 4 items $=0 \cdot 92 ; 95 \%$ CI $0 \cdot 77,1 \cdot 11$ ) were not associated with stroke, while greater variety in vegetables was also not significantly associated (HR per 2 items $=0 \cdot 93 ; 95 \%$ CI $0 \cdot 83,1 \cdot 04)$.
Within participants enrolled from 1994 onwards ( $n$ 15 433), the HR for incident CHD and stroke did not change after adjustment for physical activity. For example, the HR for incident CHD changed from 1.06 (95\% CI 0.61, 1.36) to $1.05(95 \%$ CI $0.58,1.92)$ after adjustment for physical activity for high $v$. low variety in fruit and vegetable consumption. 
Table 3 Hazard ratios (HR) and $95 \%$ confidence intervals* of incident $\mathrm{CHD}$ by tertile of variety in fruit and vegetable consumption among 20069 Dutch men and women aged 20-65 years

\begin{tabular}{|c|c|c|c|c|c|c|c|}
\hline & \multirow{2}{*}{$\frac{\mathrm{T} 1}{\mathrm{HR}}$} & \multicolumn{2}{|c|}{$\mathrm{T} 2$} & \multicolumn{2}{|c|}{ T3 } & \multicolumn{2}{|c|}{ Continuously } \\
\hline & & $\mathrm{HR}$ & $95 \% \mathrm{Cl}$ & $\mathrm{HR}$ & $95 \% \mathrm{Cl}$ & $\mathrm{HR}$ & $95 \% \mathrm{Cl}$ \\
\hline \multicolumn{8}{|c|}{ Fruit and vegetables } \\
\hline Variety score & $\leq 8$ & \multicolumn{2}{|c|}{$9-12$} & \multicolumn{2}{|c|}{$\geq 13$} & \multicolumn{2}{|c|}{ Per 4 items } \\
\hline$n$ & 6768 & \multirow{2}{*}{\multicolumn{2}{|c|}{$\begin{array}{c}6571 \\
84\end{array}$}} & \multirow{2}{*}{\multicolumn{2}{|c|}{$\begin{array}{c}6730 \\
57\end{array}$}} & & \\
\hline No. of cases & 104 & & & & & \multicolumn{2}{|c|}{245} \\
\hline Model 1 & $1 \cdot 00$ & $0 \cdot 87$ & $0 \cdot 65,1 \cdot 17$ & 0.65 & $0.47,0.90$ & $0 \cdot 86$ & $0.77,0.98$ \\
\hline Model 2 & $1 \cdot 00$ & 0.99 & $0 \cdot 73,1 \cdot 33$ & $0 \cdot 77$ & $0.55,1.09$ & 0.93 & $0.82,1.06$ \\
\hline Model 3 & $1 \cdot 00$ & $1 \cdot 10$ & $0 \cdot 80,1 \cdot 53$ & 0.99 & $0.63,1.57$ & $1 \cdot 07$ & $0 \cdot 89,1 \cdot 29$ \\
\hline \multicolumn{8}{|l|}{ Fruit } \\
\hline Variety score & $\leq 3$ & \multirow{2}{*}{\multicolumn{2}{|c|}{$\begin{array}{c}4-6 \\
6156\end{array}$}} & \multirow{2}{*}{\multicolumn{2}{|c|}{$\begin{array}{c}\geq 7 \\
6393\end{array}$}} & \multirow{2}{*}{\multicolumn{2}{|c|}{ Per 2 items }} \\
\hline$n$ & 7520 & & & & & & \\
\hline No. of cases & 123 & \multicolumn{2}{|c|}{67} & \multicolumn{2}{|c|}{55} & \multicolumn{2}{|c|}{245} \\
\hline Model 1 & $1 \cdot 00$ & 0.66 & $0 \cdot 49,0 \cdot 89$ & 0.56 & $0 \cdot 41,0 \cdot 78$ & 0.87 & $0.80,0.95$ \\
\hline Model 2 & $1 \cdot 00$ & $0 \cdot 76$ & $0.56,1.03$ & $0 \cdot 70$ & $0.50,0.98$ & 0.93 & $0.85,1.02$ \\
\hline Model 3 & $1 \cdot 00$ & $0 \cdot 81$ & $0 \cdot 58,1 \cdot 13$ & $0 \cdot 80$ & $0 \cdot 50,1 \cdot 29$ & $1 \cdot 00$ & $0 \cdot 87,1 \cdot 15$ \\
\hline \multicolumn{8}{|l|}{ Vegetables } \\
\hline Variety score & $\leq 4$ & \multirow{2}{*}{\multicolumn{2}{|c|}{$\begin{array}{c}5-7 \\
7699\end{array}$}} & \multirow{2}{*}{\multicolumn{2}{|c|}{$\begin{array}{c}\geq 8 \\
5877\end{array}$}} & \multicolumn{2}{|c|}{ Per 2 items } \\
\hline$n$ & 6493 & & & & & & \\
\hline No. of cases & 90 & \multicolumn{2}{|c|}{89} & \multicolumn{2}{|c|}{66} & \multicolumn{2}{|c|}{245} \\
\hline Model 1 & $1 \cdot 00$ & 0.94 & $0 \cdot 70,1 \cdot 26$ & $1 \cdot 01$ & $0 \cdot 73,1 \cdot 39$ & 0.98 & $0.89,1.08$ \\
\hline Model 2 & 1.00 & 0.98 & $0 \cdot 73,1 \cdot 32$ & 1.09 & $0 \cdot 78,1 \cdot 51$ & $1 \cdot 00$ & $0.90,1.11$ \\
\hline Model 3 & $1 \cdot 00$ & $1 \cdot 03$ & $0 \cdot 76,1 \cdot 40$ & $1 \cdot 26$ & $0 \cdot 89,1 \cdot 79$ & $1 \cdot 05$ & $0 \cdot 94,1 \cdot 17$ \\
\hline
\end{tabular}

${ }^{*} \mathrm{HR}(95 \% \mathrm{Cl})$ obtained from Cox proportional hazards models. Model 1 was adjusted for age and gender $(n 20069)$. Model 2 was the same as model 1 with additional adjustments for energy intake, alcohol intake, smoking status, educational level, dietary supplement use, use of hormone replacement therapy, family history of acute myocardial infarction and BMI ( $n$ 19819). Model 3 was the same as model 2 with additional adjustment for intakes of wholegrain foods, processed meat and fish and quantity of fruit and vegetable consumption ( $n$ 19819).

Table 4 Hazard ratios (HR) and $95 \%$ confidence intervals* of incident stroke by tertile of variety in fruit and vegetable consumption among 20069 Dutch men and women aged 20-65 years

\begin{tabular}{|c|c|c|c|c|c|c|c|}
\hline & \multirow{2}{*}{$\frac{\mathrm{T} 1}{\mathrm{HR}}$} & \multicolumn{2}{|c|}{$\mathrm{T} 2$} & \multicolumn{2}{|c|}{ T3 } & \multicolumn{2}{|c|}{ Continuously } \\
\hline & & $\mathrm{HR}$ & $95 \% \mathrm{Cl}$ & $\mathrm{HR}$ & $95 \% \mathrm{Cl}$ & $\mathrm{HR}$ & $95 \% \mathrm{Cl}$ \\
\hline \multicolumn{8}{|c|}{ Fruit and vegetables } \\
\hline Variety score & $\leq 8$ & \multicolumn{2}{|c|}{$9-12$} & \multirow{2}{*}{\multicolumn{2}{|c|}{$\begin{array}{l}\geq 13 \\
6730\end{array}$}} & \multicolumn{2}{|c|}{ Per 4 items } \\
\hline$n$ & 6768 & \multirow{2}{*}{\multicolumn{2}{|c|}{$\begin{array}{c}6571 \\
69\end{array}$}} & & & & \\
\hline No. of cases & 96 & & & \multicolumn{2}{|c|}{68} & \multicolumn{2}{|c|}{233} \\
\hline Model 1 & $1 \cdot 00$ & 0.72 & $0.53,0.98$ & $0 \cdot 70$ & $0.51,0.96$ & 0.85 & $0.75,0.96$ \\
\hline Model 2 & $1 \cdot 00$ & $0 \cdot 80$ & $0 \cdot 58,1 \cdot 10$ & $0 \cdot 82$ & $0 \cdot 82,1 \cdot 14$ & 0.91 & $0.80,1.03$ \\
\hline Model 3 & $1 \cdot 00$ & $0 \cdot 83$ & $0 \cdot 59,1 \cdot 18$ & 0.90 & $0.58,1.41$ & 0.92 & $0 \cdot 77,1 \cdot 11$ \\
\hline \multicolumn{8}{|l|}{ Fruit } \\
\hline Variety score & $\leq 3$ & \multicolumn{2}{|c|}{$4-6$} & \multirow{2}{*}{\multicolumn{2}{|c|}{$\begin{array}{c}\geq 7 \\
6393\end{array}$}} & \multirow{2}{*}{\multicolumn{2}{|c|}{ Per 2 items }} \\
\hline$n$ & 7520 & \multirow{2}{*}{\multicolumn{2}{|c|}{$\begin{array}{c}6156 \\
67\end{array}$}} & & & & \\
\hline No. of cases & 99 & & & \multicolumn{2}{|c|}{$\begin{array}{c}6393 \\
67\end{array}$} & \multicolumn{2}{|c|}{233} \\
\hline Model 1 & 1.00 & $0 \cdot 77$ & $0.56,1.05$ & 0.74 & $0.54,1.01$ & 0.92 & $0.84,1.00$ \\
\hline Model 2 & $1 \cdot 00$ & 0.89 & $0.64,1.22$ & $0 \cdot 88$ & $0.63,1.22$ & 0.97 & $0.89,1.07$ \\
\hline Model 3 & 1.00 & 0.94 & $0 \cdot 67,1.33$ & 0.99 & $0.62,1.58$ & 1.03 & $0.89,1 \cdot 18$ \\
\hline \multicolumn{8}{|l|}{ Vegetables } \\
\hline Variety score & $\leq 4$ & \multicolumn{2}{|c|}{$5-7$} & \multicolumn{2}{|c|}{$\begin{array}{c}\geq 8 \\
5877\end{array}$} & \multicolumn{2}{|c|}{ Per 2 items } \\
\hline$n$ & 6493 & \multicolumn{2}{|c|}{7699} & \multirow{2}{*}{\multicolumn{2}{|c|}{$\begin{array}{c}5877 \\
50\end{array}$}} & & \\
\hline No. of cases & 91 & & & & & \multicolumn{2}{|c|}{233} \\
\hline Model 1 & $1 \cdot 00$ & 0.90 & $0 \cdot 67,1 \cdot 20$ & 0.66 & $0.46,0.93$ & 0.89 & $0.80,0.99$ \\
\hline Model 2 & 1.00 & 0.93 & $0.69,1 \cdot 24$ & $0 \cdot 70$ & $0.49,1.00$ & 0.91 & $0.82,1.01$ \\
\hline Model 3 & $1 \cdot 00$ & 0.96 & $0 \cdot 71,1 \cdot 29$ & $0 \cdot 76$ & $0 \cdot 52,1 \cdot 10$ & 0.93 & $0.83,1.04$ \\
\hline
\end{tabular}

${ }^{\star} \mathrm{HR}(95 \% \mathrm{Cl})$ obtained from Cox proportional hazards models. Model 1 was adjusted for age and gender ( $n$ 20069). Model 2 was the same as model 1 with additional adjustments for energy intake, alcohol intake, smoking status, educational level, dietary supplement use, use of hormone replacement therapy, family history of acute myocardial infarction and BMI ( $n$ 19819). Model 3 was the same as model 2 with additional adjustment for intakes of wholegrain foods, processed meat and fish and quantity of fruit and vegetable consumption ( $n$ 19819).

\section{Discussion}

In the present population-based cohort study of generally healthy men and women, we found that greater variety in fruit and vegetables was associated with higher intakes of particularly vitamin $\mathrm{C}$ as well as carotenoids, flavonoids and dietary fibre, but not with energy intake. Variety and quantity of fruit and vegetable consumption were strongly 
correlated. After adjustment for quantity, we found no relationship between variety in fruit and vegetable consumption and the risk of either incident CHD or stroke.

Major strengths of the present study are its prospective and population-based study design and large sample size. With respect to non-fatal events, it was shown on the national level that data from the Dutch hospital discharge register can be uniquely matched to an individual for at least $88 \%$ of the hospital admissions ${ }^{(27)}$. Possible misclassification is expected to be random and not related to fruit and vegetable consumption. Therefore, the strengths of the associations may have been underestimated.

We used a detailed FFQ that was validated for the intake of food groups including fruit and vegetables and they formed the basis for the variety score. Moreover, it was difficult to operationalize variety. First, the FFQ assessed only the intake of fruit and vegetable items that were most commonly consumed in the Netherlands. Second, several fruit and vegetable items were combined in single questions and could not be distinguished from one another. Third, some fruit and vegetables are typically consumed during summer or winter and their consumed frequencies were calculated as frequencies per day during the previous year. Due to these limitations, variety scores could be underestimated which may have led to little variation in variety in fruit and vegetables. Greater variety can possibly be achieved by combining different dietary assessment methods, e.g. a dietary history method and an FFQ, or by extending an FFQ with questions on less commonly consumed fruit and vegetables during the season that they were on the market ${ }^{(19)}$.

After adjustment for quantity of fruit and vegetables, we found no clear associations between variety and incident CHD or stroke. Consistent with results of previous cohort studies, we found that a more varied fruit and vegetable consumption is accompanied by higher amounts of fruit and vegetables ${ }^{(17-21)}$. Our reported correlation coefficients between variety and quantity were comparable to those found among American adults of the Nurses' Health Study and the Health Professionals' Follow-up Study $(r=0.77$ for fruits; $r=0.73$ for vegetables) ${ }^{(18)}$. It is possible that after adjustment for quantity the potential benefits of a varied fruit and vegetable consumption were overadjusted.

Fruit and vegetables are rich sources of micronutrients and bioactive phytochemicals that may play an important role in the prevention of $\mathrm{CHD}$ and stroke and are relatively low in energy density ${ }^{(28)}$. We found that more variety in fruit and vegetables was associated with higher intakes of vitamin C, carotenoids, flavonoids and dietary fibre. This is in line with a previous study showing that variety within fruit and vegetables was correlated with nutrient adequacy $^{(29)}$. Variety in fruit and vegetable consumption may promote higher intakes of total fruit and vegetables and thus micronutrients and bioactive compounds. These compounds may act synergistically to prevent CHD or stroke $^{(11)}$ and this supports the current recommendation to eat a diet rich in fruit and vegetables daily ${ }^{(12)}$.

Particularly, eating a variety of nutrient-dense foods between and within basic food groups may ensure that adequate amounts of micronutrients and bioactive compounds are consumed. This has been translated in the 2010 USDA Dietary Guidelines for Americans as 'choose a variety of fruit and vegetables daily'(12). The implication of this recommendation, however, is unclear because variety was not defined. In different studies in which variety scores were calculated based on FFQ data, different time periods were used, e.g. per month, per 2 weeks or per week, and fruit juices and sauces or herbs were included in the definition ${ }^{(17-21)}$. A clear definition of variety is urgently needed to examine the importance of variety in relation to $\mathrm{CHD}$ or stroke.

\section{Conclusions}

We found that greater variety in fruit and vegetable consumption was accompanied by higher intakes of fruit and vegetables and of micronutrients and bioactive compounds. Evidence from the present study does not support the recommendation to consume a variety of fruit and vegetables to lower CHD or stroke risk. Results from prospective cohort studies with more detailed data collected with different survey methods on variety are needed to investigate the importance of variety in the prevention of CHD and stroke.

\section{Acknowledgements}

This study was supported by a research grant from the Alpro Foundation, Belgium. The Monitoring Project on Risk Factors and Chronic Diseases in the Netherlands (MORGEN) Study was supported by the Ministry of Health, Welfare and Sport of the Netherlands, the National Institute of Public Health and the Environment, Bilthoven, the Netherlands and the Europe Against Cancer Program of the European Union. J.M.G. obtained an unrestricted grant from the Product Board for Horticulture, Zoetermeer, the Netherlands. The sponsors did not participate in the design or conduct of the study; in the collection, analysis or interpretation of the data; or in the preparation, review or approval of the manuscript. None of the authors had conflicts of interest related to any part of this study. The authors' responsibilities were as follows. Study concept and design: L.M.O.G., J.M.G. and D.K.; acquisition of data: W.M.M.V., and M.C.O.; analysis and interpretation of data: L.M.O.G., D.K. and J.M.G.; drafting of the manuscript: L.M.O.G.; critical revision of the manuscript for important intellectual content: W.M.M.V., D.K., M.C.O. and J.M.G.; statistical analysis: L.M.O.G.; obtained funding: W.M.M.V. and J.M.G.; administrative, technical or material support: W.M.M.V. and J.M.G.; study supervision: J.M.G., W.M.M.V., and D.K. 


\section{References}

1. Dauchet L, Amouyel P \& Dallongeville J (2005) Fruit and vegetable consumption and risk of stroke: a meta-analysis of cohort studies. Neurology 65, 1193-1197.

2. Dauchet L, Amouyel P, Hercberg S et al. (2006) Fruit and vegetable consumption and risk of coronary heart disease: a meta-analysis of cohort studies. J Nutr 136, 2588-2593.

3. He FJ, Nowson CA \& MacGregor GA (2006) Fruit and vegetable consumption and stroke: meta-analysis of cohort studies. Lancet 367, 320-326.

4. He FJ, Nowson CA, Lucas M et al. (2007) Increased consumption of fruit and vegetables is related to a reduced risk of coronary heart disease: meta-analysis of cohort studies. J Hum Hypertens 21, 717-728.

5. Zino S, Skeaff M, Williams S et al. (1997) Randomised controlled trial of effect of fruit and vegetable consumption on plasma concentrations of lipids and antioxidants. BMJ 314, 1787-1791.

6. Broekmans WM, Klopping-Ketelaars IA, Schuurman CR et al. (2000) Fruits and vegetables increase plasma carotenoids and vitamins and decrease homocysteine in humans. J Nutr 130, $1578-1583$.

7. John JH, Ziebland S, Yudkin P et al. (2002) Effects of fruit and vegetable consumption on plasma antioxidant concentrations and blood pressure: a randomised controlled trial. Lancet 359, 1969-1974.

8. Vivekananthan DP, Penn MS, Sapp SK et al. (2003) Use of antioxidant vitamins for the prevention of cardiovascular disease: meta-analysis of randomised trials. Lancet 361, 2017-2023.

9. Sesso HD, Buring JE, Christen WG et al. (2008) Vitamins E and $\mathrm{C}$ in the prevention of cardiovascular disease in men: the Physicians' Health Study II randomized controlled trial. JAMA 300, 2123-2133.

10. Appel LJ, Moore TJ, Obarzanek E et al. (1997) A clinical trial of the effects of dietary patterns on blood pressure. DASH Collaborative Research Group. N Engl J Med 336, $1117-1124$

11. Jacobs Jr DR, Gross MD \& Tapsell LC (2009) Food synergy: an operational concept for understanding nutrition. $\mathrm{Am} \mathrm{J}$ Clin Nutr 89, issue 5, 1543S-1548S.

12. US Department of Health and Human Services \& US Department of Agriculture (2010) Dietary Guidelines for Americans, 7th ed. Washington, DC: US Government Printing Office.

13. Oude Griep LM, Geleijnse JM, Kromhout D et al. (2010) Raw and processed fruit and vegetable consumption and 10 -year coronary heart disease incidence in a populationbased cohort study in the Netherlands. PLoS One 5, e13609.

14. Oude Griep LM, Verschuren WMM, Kromhout D et al. (2011) Colours of fruit and vegetables and 10-year incidence of coronary heart disease. BrJ Nutr 106, 1562-1569.

15. Oude Griep LM, Verschuren WMM, Kromhout D et al. (2011) Raw and processed fruit and vegetable consumption and 10 -year stroke incidence in a population-based cohort study in the Netherlands. Eur J Clin Nutr 65, 791-799.

16. Oude Griep LM, Verschuren WMM, Kromhout D et al. (2011) Colors of fruit and vegetable consumption and 10-year incidence of stroke. Stroke 42, 3190-3195.

17. Bhupathiraju SN \& Tucker KL (2011) Greater variety in fruit and vegetable intake is associated with lower inflammation in Puerto Rican adults. Am J Clin Nutr 93, 37-46.

18. Feskanich D, Ziegler RG, Michaud DS et al. (2000) Prospective study of fruit and vegetable consumption and risk of lung cancer among men and women. J Natl Cancer Inst 92, 1812-1823.

19. Jansen MCJF, Bueno-de-Mesquita HB, Feskens EJM et al. (2004) Quantity and variety of fruit and vegetable consumption and cancer risk. Nutr Cancer 48, 142-148.

20. Büchner FL, Bueno-de-Mesquita HB, Ros MM et al. (2010) Variety in fruit and vegetable consumption and the risk of lung cancer in the European Prospective Investigation into Cancer and Nutrition. Cancer Epidemiol Biomarkers Prev 19, 2278-2286.

21. Büchner FL, Bueno-de-Mesquita HB, Ros MM et al. (2010) Variety in vegetable and fruit consumption and risk of bladder cancer in the European Prospective Investigation into Cancer and Nutrition. Int J Cancer 12, 2971-2979.

22. Verschuren WMM, Blokstra A, Picavet HS et al. (2008) Cohort profile: the Doetinchem Cohort Study. Int J Epidemiol 37, 1236-1241.

23. Ocké MC, Bueno-de-Mesquita HB, Goddijn HE et al. (1997) The Dutch EPIC food frequency questionnaire. I. Description of the questionnaire, and relative validity and reproducibility for food groups. Int J Epidemiol 26, Suppl. 1, S37-S48.

24. Netherlands Nutrition Center (1996) Dutch Food Composition Database. The Hague: Netherlands Nutrition Center (in Dutch).

25. Pols MA, Peeters PH, Ocké MC et al. (1997) Estimation of reproducibility and relative validity of the questions included in the EPIC Physical Activity Questionnaire. Int J Epidemiol 26, Suppl. 1, S181-S189.

26. Merry AH, Boer JM, Schouten LJ et al. (2009) Validity of coronary heart diseases and heart failure based on hospital discharge and mortality data in the Netherlands using the cardiovascular registry Maastricht cohort study. Eur J Epidemiol 24, 237-247.

27. De Bruin A, De Bruin EL, Gast A et al. (2003) Linking Data of National Ambulant Register and GBA Data: Methods, Results and Quality Research. Voorburg: Statistics Netherlands (in Dutch).

28. Eichholzer M, Lüthy J, Gutzwiller F et al. (2001) The role of folate, antioxidant vitamins and other constituents in fruit and vegetables in the prevention of cardiovascular disease: the epidemiological evidence. Int J Vitam Nutr Res 71, 5-17.

29. Foote JA, Murphy SP, Wilkens LR et al. (2004) Dietary variety increases the probability of nutrient adequacy among adults. J Nutr 134, 1779-1785. 